\title{
PAPARAN DEBU KAYU DAN AKTIVITAS FISIK TERHADAP DAMPAK KESEHATAN PEKERJA MEUBEL
}

\author{
Herdianti $^{1 凶}{ }^{1}$, Taufik Fitriyanto ${ }^{2}$, Suroso ${ }^{3}$ \\ ${ }^{1}$ Program Studi Kesehatan Lingkungan, STIKes Ibnu Sina, Batam, Indonesia \\ ${ }^{2}$ Program Studi Kesehatan Masyarakat, STIKES Harapan Ibu, Jambi, Indonesia \\ ${ }^{3}$ Dinas Kesehatan Provinsi, Jambi, Indonesia
}

\section{ARTICLE INFO \\ Article history}

Submitted : 2018-06-30

Revised : 2018-07-17

Accepted : 2018-07-18

\section{Keywords:}

Physical Activitis

Respiratory Disorders

Exposure Dust

\begin{abstract}
Based on data from the International Labor Organization of the ILO, 1 worker dies every 15 seconds due to workplace accidents and 160 workers suffering from work-related illness. The mortality rate due to occupational accidents and occupational diseases in Indonesia is still high. Occupational disease consists of a causative agent in the workplace. This research is a quantitative descriptive research that aims to find out the description of wood dust and physical activity exposure to health at worker Furniture in CV Semoga Jaya Jambi City in 2017. Population in this research is all labor in furniture CV Semoga Jaya Jambi City 2016 which amount 31 people. Samples in total sampling that amounted to 31 people. The research process conducted on May 15 to June 10 Year 2017 in furniture CV Semoga Jaya Jambi City. Data were analyzed univariat. The result of univariate research showed that most of the respondents $(74,2 \%)$ had bad exposure (> NAB), most of them $(51,6 \%)$ had fatigue and most $(58,1 \%)$ did not suffer from respiratory problems. It is expected that workers use PPE in the form of masks to prevent exposure to dust from wood dust during work. In addition, stretching the muscles during fatigue due to monotonous work attitude. In addition, business owners need to create a special space in each room of production roses that produce wood powder to make the resulting powder not directly exposed or slightly reduce the direct exposure to wood dust dust with workers.
\end{abstract}

Corresponding Author:

Herdianti

Program Studi Kesehatan Lingkungan, STIKes Ibnu

Sina, Batam, Indonesia

Telp. 085395925901

Email: herdiantinyup@gmail.com

\section{PENDAHULUAN}

Data International Labor Organization ILO tahun 2017, 1 pekerja meninggal dunia setiap 10 detik karena kecelakaan kerja dan 130 pekerja mengalami sakit akibat kerja. Tahun sebelumnya 2016 ILO mencatat angka kematian karena kecelakaan dan penyakit akibat kerja (PAK) sebanyak 2 juta kasus setiap tahun (Kemenkes RI, 2017).

Salah satu dampak negatif dari industri pengolahan kayu adalah timbulnya pencemaran udara oleh debu yang timbul pada proses pengolahan atau hasil industri tersebut. Debu kayu ini akan mencemari daerah industri dan lingkungannya sehingga pekerja maupun masyarakat di sekitar industri dapat terpapar oleh debu baik karena bahan baku, bahan antara ataupun produk akhir. Bahan pencemar tersebut dapat berpengaruh terhadap lingkungan dan manusia (Anderson, 2010).

Debu kayu atau wood dust dihasilkan dari pengolahan atau penanganan kayu, seperti pemotongan, pengampelasan, atau penyerutan. Meski tidak semua dapat membahayakan kesehatan (tergantung dari spesies kayu yang digunakan), debu kayu ini tetap bisa menjadi ancaman bagi pekerja yang setiap harinya terpajan debu kayu yang memiliki kandungan bahan toksik (Bohadana, 2015).

Pada dasarnya debu kayu sama dengan karakteristik debu pada umumnya, hanya komponen dan ukurannya saja yang berbeda sehingga pengaruh yang ditimbulkan debu kayu terhadap kesehatan pekerja juga tidak jauh 
berbeda dengan pengaruh yang ditimbulkan oleh debu pada umumnya (Asiah, 2016).

Menurut Keputusan Menteri Kesehatan

Nomor 1405/Menkes/SK/XV/2002, pada lampiran I tentang Persyaratan dan tata cara penyelenggaraan kesehatan lingkungan kerja perkantoran. Adapun kandungan debu maksimal di dalam udara ruangan dalam pengukuran debu rata-rata 8 jam adalah $0,15 \mathrm{mg} / \mathrm{m}^{3}$. Baik hardwood maupun softwood digolongkan sebagai bahan karsinogenik dan dianggap sebagai pencetus kanker. Oleh karena itu, paparan debu kayu di area kerja harus dalam batas aman dan tidak melebihi batas maksimalnya (Kemenkes RI, 2017).

Menurut hasil penelitian dari

Deviandhoko dkk, 2012 menunjukkan terdapat hubungan yang signifikan antara kadar debu terhirup dengan fungsi paru. Hasil Peneltian Dinda dkk 2013 menyatakan bahwa ada hubungan anatara kadar debu urea di lingkungan kerja dengan infeksi saluran pernafasan akut (ISPA) pada pekerja di unit PPU PT. Pusri.

Hasil penelitian yang dilakukan Suryani menunjukkan bahwa jumlah abu kayu di WWA dan FC dari $6.1452 \mathrm{mg} / \mathrm{m} 3$ dan $4.0101 \mathrm{mg} / \mathrm{m} 3$ masing-masing; dan rata-rata kapasitas fungsi paru-paru pada pekerja adalah 92,04\% FEV1/FVC dengan standar deviasi 6,68 dengan terendah dan tingkat tertinggi $66 \%$ FEV1/FVC dan 100\% FEV1/FVC (Suryani, 2005).

Berdasarkan data jumlah tenaga kerja di meubel Wilayah Kerja Puskesmas Kebun Kopi tahun 2016 sebanyak 193 orang. Jumlah tenaga kerja terbanyak yaitu di bagian tukang amplas sebanyak 31 orang.

Berdasarkan Survey awal diperoleh informasi bahwa Meubel CV Semoga Jaya merupakan industri mebel yang mengolah mebel yang masih kasar menjadi mebel yang siap pakai atau sudah menjadi furniture. Dalam proses alur produksi mebel hingga menjadi mebel siap pakai, industri mebel juga menghasilkan limbah salah satunya yaitu debu kayu yang di hasilkan dari proses produksi. Debu kayu jika tidak di perhatikan dengan benar dapat mengancam kesehatan kerja terutama sistem pernafasan jika secara terusmenerus terhirup masuk kedalam paru akan mengakibatkan menurunya kapasitas fungsi paru. Berdasarkan hasil pengukuran lingkungan pada bagian produksi dilakukan pada 3 (tiga) titik. Titik pertama di tempat pengecatan dengan hasil kadar debu kayu 5,34 mg/m, pada titik kedua di ruang pengamplasan dengan hasil kadar debu kayu sebesar $5,94 \mathrm{mg} / \mathrm{m}^{3}$ dan pada titik ketiga di ruang penyuguh dengan hasil kadar debu kayu sebesar $5,14 \mathrm{mg} / \mathrm{m}^{3}$ maka dengan hasil tersebut bagian produksi di atas NAB. Dengan survei yang dilakukan peneliti pekerja tersebut bekerja 8 jam selama 6 hari. Hasil wawacara dengan 2 pekerja sering mengalami batuk-batuk dan sesak napas, hal ini diakibatkan karena kondisi lingkungan yang berdebu.

Berdasarkan kondisi tersebut perlu dilakukan penelitian tentang dampak paparan debu dan aktifitas pekerja terhadap keluhan kesehatan. Kebaruan dari penelitian ini adalah untuk pertama kalinya dilakukan di wilayah kerja Puskesmas Kebun Kopi.

\section{METODE PENELITIAN \\ Jenis Penelitian}

Penelitian ini merupakan penelitian deskriptif kuantitatif dengan metode deskriptif untuk mengetahui gambaran paparan debu kayu dan aktivitas fisik terhadap kesehatan pada pekerja Meubel di CV Semoga Jaya Kota Jambi tahun 2017.

\section{Lokasi dan Waktu Penelitian}

Penelitian ini telah dilakukan di meubel Wilayah Kerja Puskesmas Kebun Kopi Kota Jambi pada tanggal 15 Mei - 10 Juni 2017.

\section{Populasi dan Sampel}

Populasi dalam penelitian ini adalah seluruh tenaga kerja bagian pengamplasan di meubel CV Semoga Jaya Kota Jambi tahun 2016 yang berjumlah 31 orang. Sampel pada penelitian ini diambil menggunakan teknik pengambilan sampel secara total sampling yaitu seluruh tenaga kerja di meubel CV Semoga Jaya Kota Jambi tahun 2016 yang berjumlah 31 orang.

Sampel yang terpilih telah dilakukan cek riwayat kesehatan berdasarkan data dari puskesmas yang menunjukkan semua sampel tidak memiliki riwayat ISPA, asma atau gangguan pernafasan lainnya sehingga tidak akan mengganggu hasil dari penelitian.

\section{Pengumpulan Data}

Pengumpulan data menggunakan instrument penelitian berupa kuesioner. 
Kuesioner yang digunakan telah dilakukan uji validitas dan realibilitas terlebih dahulu di wilayah yang memiliki karakteristik hamper sama dengan wilayah penelitian.

Gangguan pernafasan dan aktifitas diukur dengan menggunakan kuesioner yang telah valid dan dibantu dengan cek fisik oleh staff puskesmas Kebun Kopi. Hal ini dilakukan untuk mendukung hasil kuesioner.

\section{Pengolahan dan Analisis Data}

Data dianalisis secara univariat dan diinterpretasikan dalam bentuk tekstular dan tabular.

\section{HASIL}

Gambaran aktivitas fisik pada pekerja menunjukkan bahwa responden lebih banyak yang beraktivitas ringan yaitu sebanyak 17 responden $(54,8 \%)$ (Tabel 1).

Tabel 1. Distribusi Responden berdasarkan Aktivitas Fisik Pada Pekerja Meubel di CV Semoga Jaya Kota Jambi Tahun 2017

\begin{tabular}{lcc}
\hline \multicolumn{1}{c}{ Aktivitas Fisik } & Frekuensi (orang) & Persentase (\%) \\
\hline Aktivitas Berat & 14 & 45,2 \\
Aktivitas Ringan & 17 & 54,8 \\
\hline Total & 31 & 100,0 \\
\hline
\end{tabular}

Gambaran kesehatan pekerja meubel menunjukkan bahwa responden lebih banyak yang tidak mengalami gangguan pernapasan yaitu sebanyak 18 responden $(51,8 \%)$ (Tabel
2). Gambaran paparan debu menunjukkan bahwa paparan debu dari 31 pengukuran ditemukan lebih banyak $17(63 \%)$ kali pengukuran tidak memenuhi syarat (Tabel 3).

\section{Tabel 2. Distribusi Kesehatan Pekerja Meubel di CV Semoga Jaya Kota Jambi} Tahun 2017

\begin{tabular}{ccc}
\hline Kesehatan Pekerja & Frekuensi (orang) & Persentase (\%) \\
\hline Gangguan pernapasan & 13 & 41,9 \\
Tidak mengalami gangguan pernapasan & 18 & 58,1 \\
\hline Total & 31 & 100,0 \\
\hline
\end{tabular}

Tabel 3. Distribusi Responden berdasarkan Paparan Debu di CV Semoga Jaya Kota Jambi Tahun 2017

\begin{tabular}{ccc}
\hline Paparan Debu & Frekuensi (orang) & Persentase (\%) \\
\hline Tidak memenuhi syarat & 17 & 63,0 \\
Memenuhi syarat & 10 & 37,0 \\
\hline Total & 31 & 100,0
\end{tabular}

\section{PEMBAHASAN}

Gambaran Paparan Debu Kayu di CV Semoga Jaya Kota Jambi Tahun 2017

Hasil penelitian gambaran paparan debu kayu di tempat pengecatan CV. Semoga Jaya Kota Jambi tahun 2017 menunjukkan bahwa pengukuran yang dilakukan tiga kali yaitu pagi, siang dan sore hari, dan peneliti melakukan pengukuran ditiga titik di tempat pengecatan luar ruangan didapat bahwa paparan debu yang terendah adalah pada sore hari dititik ketiga
3,26 mikron. Tempat pengamplasan luar ruangan didapat bahwa paparan debu yang terendah adalah pada siang hari dititik kedua 3,37 mikron dan tempat penyuguh didapat bahwa paparan debu yang terendah adalah pada pagi hari dititik kedua 4,99 mikron.

Hasil gambaran paparan debu di CV Semoga Jaya Kota Jambi tahun 2017 menunjukkan bahwa paparan debu dari 27 pengukuran ditemukan lebih banyak 17 (63\%) kali pengukuran tidak memenuhi syarat. 
Hasil penelitian ini didukung oleh penelitian yang dilakukan Suryani "Analisis Faktor Risiko Paparan Debu Kayu Terhadap Gangguan Fungsi Paru Pada Pekerja Industri Pengolahan Kayu PT. Surya Sindoro Sumbing Wood Industry Wonosobo. Penelitian ini menunjukkan bahwa jumlah abu kayu di WWA dari $6.1452 \mathrm{mg} / \mathrm{m} 3$ dan $4.0101 \mathrm{mg} / \mathrm{m} 3$ masingmasing; dan rata-rata kapasitas fungsi paru-paru pada pekerja adalah 92,04\% FEV1/FVC dengan standar deviasi 6,68 dengan terendah dan tingkat tertinggi $66 \%$ FEV1/FVC dan $100 \%$ FEV1/FVC masing-masing (Suryani, 2005).

Hasil penelitian ini didukung oleh penelitian yang dilakukan Yolanda (2013). Dari hasil pengukuran dengan menggunakan spirometri didapatkan bahwa 6 orang pekerja pabrik pembuatan mebel di CV Kochi Sohor yang terpapar debu setiap harinya pada waktu kerja. Hasil penelitian tersebut di atas sesuai dengan hasil Lestari (2017) yang menunjukkan terdapat hubungan yang bermakna antara paparan debu tinggi dengan terjadinya kelainan faal ventilasi paru yang mempengaruhi pernapasan.

Hasil penelitian ini juga didukung oleh penelitian yang dilakukan Khumaidah tentang analisis faktor-faktor yang berhubungan dengan gangguan fungsi paru pada pekerja mebel $\mathrm{Pt}$ Kota Jati Furnindo Desa Suwawal Kecamatan Mlonggo Kabupaten Jepara. Pengukuran kadar debu perseorangan pada pekerja mebel bagian pengamplasan diadapatkan hasil sebanyak 24 pekerja yang terpapar debu diatas NAB (dari 1 $\mathrm{mg} / \mathrm{m} 3$ ) terdapat $17(70,8 \%)$, dan 20 pekerja yang terpapar debu dibawah NAB (kurang dari $1 \mathrm{mg} / \mathrm{m} 3$ ) terdapat $2(10 \%)$ orang (Khumaidah, 2009).

Semakin kecil ukuran partikel debu maka semakin berbahaya bagi kesehatan, karena dapat terhirup dan mengendap di paruparu, ukuran partikel debu yang berbahaya bagi kesehatan adalah 0,1 mikron sampai dengan 10 mikron. Debu yang terhirup dalam jumlah yang berlebihan oleh saluran pernafasan dapat menyebabakan gangguan pada saluran pernafasan dan rasa tidak nyaman pada saat bekeja (Bohadana, 2015).

Debu kayu atau wood dust dihasilkan dari pengolahan atau penanganan kayu, seperti pemotongan, pengampelasan, atau penyerutan. Meski tidak semua dapat membahayakan kesehatan (tergantung dari spesies kayu yang digunakan), debu kayu ini tetap bisa menjadi ancaman bagi pekerja yang setiap harinya terpajan debu kayu yang memiliki kandungan bahan toksik (Safety, 2016).

Gangguan pernapasan akibat kerja atau occupational asthma terjadi karena pekerja menghirup debu kayu di tempat kerja. Debu kayu ini disebut sebagai "respiratory sensitisers" atau asthmagens, yakni agen biologi dan kimia penyebab penyakit pernapasan pada manusia. Kebanyakan pekerja memang tidak menyadari bahwa dirinya bisa terkena gangguan pernapasan akibat paparan debu kayu terus-menerus (Safety, 2016).

Dari hasil pengolahan data ditemukan bahwa hasil pengukuran kadar debu perseorangan pada pekerja didapatkan dari hasil pengukuran lingkungan kerja bahwa pekerja dibagian proses pengolahan bahan mentah menjadi bahan baku, proses produksi dan perakitan, serta proses pendempulan dan pengamplasan mempunyai $\mathrm{NAB}$ yang tinggi $(\geq$ NAB). Paparan debu yang rendah $(<\mathrm{NAB})$ yaitu pada proses fisihing awal pada proses pemlituran, pengecatan dan pengkilapan mebel jadi, serta pemasangan aksesoris seperti kain, busa spoon dan lain-lain yang dibutuhkan mebel.

Kadar debu pada proses pengolahan bahan mentah menjadi bahan baku, proses produksi dan perakitan ditemukan tinggi karena sisa dari bahan kayu yang di potong menimbulkan serbuk gergaji dan kayu yang diserut menibulkan debu kayu hasil serutan dalam bentuk yang kasar. Sedangkan pada proses pengamplasan, debu yang dihasilkan sangat lembut dari hasil pengamplasan kayu dan dempul sehingga permukaan menjadi halus. Kurangnya menjaga kebersihan seperti debu yang ada di ruangan kerja hanya disapu ke pinggir setelah tertumpuk banyak baru dibuang. Selain itu juga, ruangan pada proses pengolahan bahan mentah menjadi bahan baku, serta proses produksi dan perakitan ruangan terletak di belakang dan keduanya menyatu sementara ruangan sedikit terbuka sehingga ada hembusan angin yang menerbangkan debu-debu yang ada di ruangan tersebut sementara pembuangan limbah pada bagian ini juga masih menyatu dengan ruangan tersebut bersama dengan pekerja lain karena beluma da ruangan bagian tertentu untuk memisahkan limbah debu dari hasil pemotongan gergaji maupun penyerutan kayu.

Begitu juga dengan proses pengamplasan, meski berbeda dengan ruangan di atas, namun kondisi masih sama. Bedanya 
pengamplasan di lakukan di ruangan yang tertutup, akan tetapi debu dapat berterbangan karena ada hembusan angin dari kipas yang dipasang agar pekerja tidak kepanasan. Namun karena tidak ada ruangan pembuangan pada bagian belakang tempat keluar debu yang sangat halus dari proses pengamplasan, maka pekerja tetap berisiko terpapar debu yang bertebangan hasil dari proses pengamplasan.

Oleh sebab itu, mengingat masih banyaknya resiko pekerja mebel yang terpapar pada proses pengolahan bahan mentah menjadi bahan baku, proses produksi dan perakitan, serta proses pendempulan dan pengamplasan, terlebih lagi pada ruiangan tersebut memiliki $\mathrm{NAB}$ yang tinggi $(\geq \mathrm{NAB}$ ), maka diharapkan pelaku usaha mewajibkan pekerjanya menggunakan APD berupa masker dan sarung tangan agar tidak terpapar oleh debu pada saat bekerja. Selain itu, menjaga kebersihan ruangan dengan cara membersihkan (housekeeping) yang tidak terlaksana dengan baik perlu ditingkatkan dengan melakukan prinsip housekeeping agar pekerjaan nyaman dan berjalan dengan baik. selain itu, perlunya penambahan ruangan untuk pembuangan libah debu yang dihasilkan dari proses pembuatan mebel yang tersedia di setiap ruangan untuk mengurangi paparan debu bagi para pekerja.

\section{Gambaran Aktivitas Fisik Pekerja Meubel di CV Semoga Jaya Kota Jambi Tahun 2017}

Hasil penelitian gambaran aktivitas fisik pekerja meubel di CV Semoga Jaya Kota Jambi tahun 2017 menunjukkan bahwa responden lebih banyak yang beraktivitas ringan. Hasil ini didukung oleh hasil kuesioner bahwa responden selama bekerja sering duduk yaitu sebanyak (71\%) dan selama bekerja responden sering mengangkat beban berat yaitu sebanyak $(58,1)$ dan setelah bekerja responden berkeringat yaitu sebanyak $(77,4)$, hal inilah yang menyebabkan responden lebih banyak yang mengalami aktivitas berat.

Aktivitas fisik adalah setiap gerakan tubuh yang dihasilkan oleh otot rangka yang memerlukan pengeluaran energi. Aktivitas fisik yang tidak ada (kurangnya aktivitas fisik) merupakan faktor risiko independen untuk penyakit kronis, dan secara keseluruhan diperkirakan menyebabkan kematian secara global. Aktivitas fisik berlebih Aktivitas fisik yang berlebih juga dapat menjadi pemicu terjadinya serangan gangguan pernapasan, kelelahan tubuh menjadikan penurunan sistem imun sehingga menjadikan penderita gangguan pernapasan rentan terhadap serangan gangguan pernapasan (Irianto, 2014).

Hasil penelitian menunjukkan bahwa aktivitas fisik pada pekerja meubel adalah beraktivitas yang berlebih seperti mengangkat beban yang berat seperti kayu dan posisi pekerja yanng monoton. Temuan dari hasil penelitian, pada proses pengolahan bahan mentah menjadi bahan baku, serta proses produksi dan perakitan, kegiatan kerja yang dikaitkan dengan posisi pekerja dalam bekerja masih banyak kurang baik. hal ini terlihat adanya kegiatan pekerja yang monoton berdiri maupun duduk, sementara pergerakan lainnya kurang sehingga otot yang bekerja sering kaku karena kurangnya pergerakan lain seperti berjalan. Tingkat berat aktivitas fisik dipengaruhi juga karena pada proses pengolahan bahan mentah menjadi bahan baku, serta proses produksi dan perakitan merupakan pekerjaan yang berat dalam proses pembuatan mebel karena energi atau tenaga yang dibutuhkan lebih besar dibanding proses lainnya dalam pembuatan mebel, terlebih masih mengandalkan alat-alat yang ahrus dijalankan dnegan tenaga manusia, seperti menganggkat beban berat berupa bahan-bahan yang akan dijadikan mebel.

Sikap pekerja yang memaksakan diri karena kelelahan seperti menggergaji sambil duduk tentu akan menyebabkan pengeluaran energi yang lebih besar dibandingkan berdiri. Sikap pekerja tidak harus monoton karena bisa melakukan istirahat jika tubuh mulai kelelahan. Sikap pekerja dalam menghaluskan meubel setengah jadi monoton yakni jongkok dan membungkuk sehingga hal tersebut juga dapat menyebabkan kelelahan.

Oleh sebab itu, dalam pengaturan sikap pekerja, harus menyadarkan pekerja untuk tidak memaksakan diri dalam bekerja namun harus memperhatikan kemampuan fisik dengan mengurangi jam kerja dan lebih banyak istirahat setelah bekerja dan mengurangi mengangkat beban mentah. Kemudian, untuk menghindari rasa lelah juga perlu mengubah posisi kerja supaya tidak monoton sehingga ada pergerakan yang tidak monoton yang membuat kaku otot karena posisi kerja yang monoton.

\section{Gambaran Kesehatan Pekerja Meubel di CV Semoga Jaya Kota Jambi Tahun 2017}

Hasil penelitian gambaran kesehatan pekerja meubel di CV Semoga Jaya Kota Jambi 
tahun 2017 menunjukkan bahwa responden lebih banyak yang tidak mengalami gangguan pernapasan. Hasil penelitian ini sejalan dengan penelitian yang dilakukan oleh Zilfa Yenny dalam penelitiannya yang berjudul "Hubungan Debu Kayu Dengan Gangguan pernapasan Kerja Pada Pekerja Mebel Sektor Informal di Kelurahan Jatinegara Kecamatan Cakung". Hasil penelitian menunjukkan bahwa 24 orang $(17,8 \%)$ adalah penderita gangguan pernapasan, dengan gangguan pernapasan kerja $11,11 \%$ dan gangguan pernapasan yang diperburuk oleh kerja sebesar 6,67\% (Zilfa, 2014).

Hasil penelitian ini sejalan dengan penelitian yang dilakukan oleh Sholikhah hubungan karakteristik pekerja dan kadar debu total dengan keluhan pernapasan pada pekerja industri kayu X di Kabupaten Lumajang. Hasil identifikasi keluhan pernapasan yang dialami oleh pekerja Unit $\mathrm{X}$ menunjukkan bahwa responden yang mengalami keluhan pernapasan sebesar $87,67 \%$, sedangkan pekerja yang tidak mengalami keluhan pernapasan sebesar $12,33 \%$ (Sholikhah, 2015).

Gangguan pernapasan akibat kerja tidak timbul pada pekerja, sangat penting upaya teknis-teknologi pengendalian kadar pencemar bahan dalam udara ruang kerja. Juga penting dilakukan upaya perlindungan kepada pekerja dengan kebiasaan menggunakan alat pelindung pernafasan yang tepat. Program kesehatan kerja mencegah agar pekerja yang rentang terhadap efek palutan seperti perorangan yang atopik dan penderita penyakit radang paru kronis tidak berada dalam risiko tinggi menderita penyakit tersebut dan diterapkan deteksi dini terhadap pekerja yang terkena gangguan pernapasan akibat kerja sehingga upaya preventif dan juga promotif dapat diselenggarakan lebih efektif (Suma'mur, 2009).

Temuan dari hasil penelitian kejadian gangguan pernapasan pada pekerja yang paling sedikit yaitu kejadian mengi pada saat menghirup napas karena sebagian besar 41,9\% pekerja tidak pernah mengalaminya. Gejala gangguan pernapasan yang banyak dialami pekerja yaitu riwayat batuk karena tidak menggunakan masker pada saat bekerja sehingga dimungkinkan karena adanya debu yang terhirup saat bernafas. Begitu juga dengan gejala hambatan pernafasan dan alergen juga banyak dialami pekerja terutama pekerja bagian proses pengolahan bahan mentah menjadi bahan baku, proses produksi dan perakitan, serta proses pendempulan dan pengamplasan.

Oleh sebab itu, pentingnya penggunaan APD berupa masker bagi para pekerja untuk mencegah debu terhirup saat bernafas, maka perlu adanya penyediaan dan penyadaran bagi pekerja untuk menggunakan masker dan masker yang digunakan harus tetap memperhatikan kenyamanan serta keamanan fungsinya dalam mencegah paparan debu saat bernafas.

\section{KESIMPULAN DAN SARAN}

Berdasarkan hasil penelitian dan uraian dalam pembahasan tentang gambaran paparan debu kayu dan aktivitas fisik terhadap kesehatan pada pekerja Meubel di CV Semoga Jaya Kota Jambi tahun 2017, maka dapat ditarik beberapa kesimpulan bahwa sebagian besar $(74,2 \%)$ responden dengan paparan debu tidak memenuhi syarat $(\geq \mathrm{NAB})$, sebagian besar $(54,8 \%)$ responden beraktivitas ringan, sebagian besar $(58,1 \%)$ responden tidak mengalami gangguan pernapasan.

Diharapkan Puskesmas agar rutin melaksanakan pemeriksaan kesehatan pekerja dan lebih tegas menerapkan aturan standar untuk perlindungan kesehatan pekerja meubel.

\section{DAFTAR PUSTAKA}

Asiah, Hendrawati. (2016). Pengaruh debu kayu terhadap paru dan faktor-faktor risikonya di kalangan pekerja industri permebelan kayu PT X di Bogor. Journal Respiratory Indonesia vol 18, No. 4:137145.

Anderson. 2010. Pulmonary Manifestation in Cement Workers in Jordan. Intenational Journal Occup Med Environ Health, 10:417-428.

Bohadana, A.B, et al. (2015). Symptoms Airway Responsiveness and Exposure to Dust in Beech and Oak Wood Workers. Occup Environ Med Journal,57:268-273.

Harrianto. (2010). Buku Ajar Kesehatan Kerja. Penerbit Buku Kedokteran EGC. Jakarta.

Irianto. (2014). Ekologi Kesehatan. Penerbit Alfabeta. Bandung.

Jamsostek. (2013). Analisis Pelaksanaan K3. Jakarta.

Kemenkes RI. (2014). Orang Pekerja di Dunia Meninggal setiap 15 Detik karena Kecelakaan Kerja. Jakarta.

Kemenkes RI. (2017). Persyaratan dan tata cara penyelenggaraan kesehatan lingkungan kerja perkantoran. Jakarta. 
Khumaidah. (2009). Analisis Faktor-faktor Yang Berhubungan dengan Gangguan Fungsi Paru Pada Pekerja Mebel Pt Kota Jati Furnindo Desa Suwawal Kecamatan Mlonggo Kabupaten Jepara. Tesis. Universitas diponegoro semarang.

Safety. (2016). Dampak Buruk Paparan Debu Kayu Bisa Sebabkan Occupational Asthma.

Sholikhah. (2015). Hubungan Karakteristik Pekerja Dan Kadar Debu Total dengan Keluhan Pernapasan Pada Pekerja Industri Kayu X di Kabupaten Lumajang. Departemen Kesehatan Lingkungan Fakultas Kesehatan Masyarakat Universitas Airlangga. Perspektif jurnal Kesehatan Lingkungan Vol. 1, No. 1 Januari 2015: 1-12.

Sucipto. (2014). Sumber Daya Manusia. Penerbit PT Buku Seru. Yogyakarta.
Suma'mur. (2009). Higiene Perusahaan dan Kesehatan Kerja (Hiperkes) Penerbit Sagung Seto. Jakarta.

Suryani. (2005). Analisis Faktor Risiko Paparan Debu Kayu Terhadap Gangguan Fungsi Paru Pada Pekerja Industri Pengolahan Kayu PT. Surya Sindoro Sumbing Wood Industry Wonosobo. Skripsi.

Rickim. (2005). Kesehatan Lingkungan. Penerbit Graha Ilmu. Yogyakarta: xii + $118 \mathrm{hlm}$.

Zilfa. (2014). Hubungan Debu Kayu Dengan Gangguan pernapasan Kerja Pada Pekerja Mebel Sektor Informal di Kelurahan Jatinegara Kecamatan Cakung. Skripsi. 